\title{
Surgical multidisciplinary approach of orbital complications of sinonasal inflammatory disorders
}

\section{Approccio chirurgico multidisciplinare nel management delle complicanze orbitarie delle patologie infiammatorie naso-sinusali}

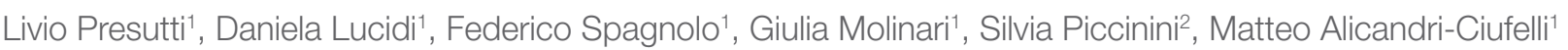 \\ ${ }^{1}$ Otolaryngology, Head and Neck Surgery Department, Policlinico di Modena, University of Modena and Reggio Emilia, Italy; \\ ${ }^{2}$ Neuroradiology Department, Nuovo Ospedale Civile Sant'Agostino Estense, Modena, Italy
}

\begin{abstract}
SUMMARY
Orbital infection complicating sinonasal inflammatory disorders may lead to serious sequelae, including blindness and death, if untreated. Communication between the otorhinolaryngologist, neuroradiologist, ophtalmologist, neurosurgeon and maxillo-facial surgeon is critical and time-sensitive for a successful treatment. The large majority of pre-septal cellulitis cases resolves after broad-spectrum antibiotic therapy. Also orbital cellulitis has been found responsive to pharmacological approach in most cases. The management of the subperiosteal abscess (SPA) is more controversial. An aggressive surgical approach is always recommended also in case of cavernous sinus thrombosis. In cases of surgical indication, debate is still open on the timing and the approach (endoscopic or external). The surgeon should be prepared to convert an endoscopic approach to an external one if needed and this should be included in the informed consent. Decompression of one or more orbital walls may be necessary if orbital pressure remains elevated. Immediate surgery is indicated in children with large SPA or orbital abscesses (OA), or in immune-compromised patients. Moreover, any worsening in the ophthalmological function must be carefully considered as a landmark in candidacy to surgery.
\end{abstract}

KEY WORDS: sinusitis, orbit, Chandler's classification, orbital abscess, orbital cellulitis

\section{RIASSUNTO}

L'infezione orbitaria come complicanza di una patologia infiammatoria nasosinusale può portare a gravi sequele, incluse cecità e morte, se non trattata. La comunicazione tempestiva e diretta tra l'otorinolaringoiatra, il neuroradiologo, l'oculista, il neurochirurgo e il chirurgo maxillo-facciale è fondamentale per garantire un trattamento di successo. Le celluliti pre-settali si risolvono con terapia antibiotica ad ampio spettro. Anche la cellulite orbitaria è responsiva al trattamento farmacologico nella maggior parte dei casi. Il management dell'ascesso subperiosteo (SPA) è invece controverso. Un approccio chirurgico aggressivo è sempre consigliato in caso di trombosi del seno cavernoso. Il timing e il tipo di approccio (endoscopico o esterno) sono oggetto di dibattito nella scelta chirurgica. Il chirurgo dovrebbe essere preparato a convertire un approccio endoscopico in uno esterno, se necessario. La decompressione di una o più pareti orbitarie può essere necessaria se la pressione rimane elevata. La chirurgia è immediata nei bambini con SPA o ascesso orbitario di grandi dimensioni o in pazienti immunocompromessi. Un eventuale peggioramento della funzione oftalmologica deve essere attentamente considerato come un fattore deponente per un trattamento chirurgico.

PAROLE CHIAVE: sinusite, orbita, classificazione di Chandler, ascesso orbitario, cellulite orbitaria

\section{Introduction}

Despite differential diagnosis of orbital infection is broad, sinonasal inflammatory disorders are responsible for around $75 \%$ of cases. Being surrounded
Received: November 12, 2020

Accepted: February 9, 2021

\section{Correspondence}

Daniela Lucidi

Otolaryngology, Head and Neck Surgery Department, Policlinico di Modena, University of Modena and Reggio Emilia

largo del Pozzo 71, 41125 Modena, Italy

E-mail: dani.lucidi@gmail.com

Funding

None.

Conflict of interest

The Authors declare no conflict of interest.

How to cite this article: Presutti L, Lucidi D, Spagnolo F, et al. Surgical multidisciplinary approach of orbital complications of sinonasal inflammatory disorders. Acta Otorhinolaryngol Ital 2021;41(SUPPL.1):S108-S115. https://doi. org/10.14639/0392-100X-suppl.1-41-2021-11

() Società Italiana di Otorinolaringoiatria e Chirurgia Cervico-Facciale

\section{(c) (1) $(2)$}

This is an open access article distributed in accordance with the CC-BY-NC-ND (Creative Commons Attribution-NonCommercial-NoDerivatives 4.0 International) license. The article can be used by giving appropriate credit and mentioning the license, but only for non-commercial purposes and only in the original version. For further information: https:// creativecommons.org/licenses/by-nc-nd/4.0/deed.en 
by sinuses on three sides, the orbit is susceptible to contiguous spread of infection, and notwithstanding the decreased incidence of this event in the antibiotic era, orbital infection without appropriate treatment may lead to serious sequelae, including blindness and death ${ }^{1}$.

Chandler's classification distinguishes orbital complications according to the extent of infection into the orbital content and the surrounding structures ${ }^{2}$. Diagnostic work-up should include prompt radiological investigation, CT scan and MRI playing a complementary role in this setting ${ }^{1}$.

A crucial point in the treatment of orbital complications is whether to choose a conservative or non-conservative (surgical) protocol. In cases of surgical indication, debate is still open on the timing and the approach (open or endoscopic). Overall, clear communication between the otorhinolaryngologist, neuroradiologist, ophtalmologist, neurosurgeon and maxillo-facial surgeon is critical and time-sensitive, both in treatment planning and performance.

A review of the literature was performed to thoroughly investigate on orbital complications of sinonasal inflammatory disorders, in particular to assess which are the indications to surgical treatment and when a multidisciplinary approach is recommended or optional in the management of such complications.

\section{Anatomy}

The orbital cavity has a pyramidal shape with four walls and an apex. The superior wall is made up by the inferior surface of the frontal bone and the lesser wing of the sphenoid. On this "roof", two depressions are clearly visible: the trochlear fossa and the supraorbital foramen, through which pass the homonymous vessels and nerve. The inferior wall, which hosts the infraorbital canal, separates the orbital cavity from the maxillary sinus. The apex represents the communication between the orbit and the middle cranial fossa, and is in close relationship with the lateral wall of the sphenoid sinus. It hosts the ophthalmic artery and vein, the optic and oculomotor nerves. The lamina papyracea (LP) of the ethmoidal bone represents the medial wall, and marks the bound between the orbital cavity laterally and nasal cavity medially, representing one of the most important landmarks in functional endoscopic sinus surgery ${ }^{3}$. Further details regarding the anatomic relationship between the orbit and the sinonasal cavity are depicted in Figure 1.

\section{Physiopathology}

Local complications of sinusitis could be orbital, intracranial and osseous. The orbit is susceptible to contiguous spread of infection as it is surrounded by sinuses on three sides. This is more relevant in children, because of their thinner bony septa and sinus wall, greater porosity of bones, open suture lines, and larger vascular foramina.

Indeed, infections can spread directly by penetration of the LP through its small bony dehiscence or extend directly by traversing through the anterior and posterior ethmoidal foramina. Since the ophthalmic venous system has no valves (Brechet's

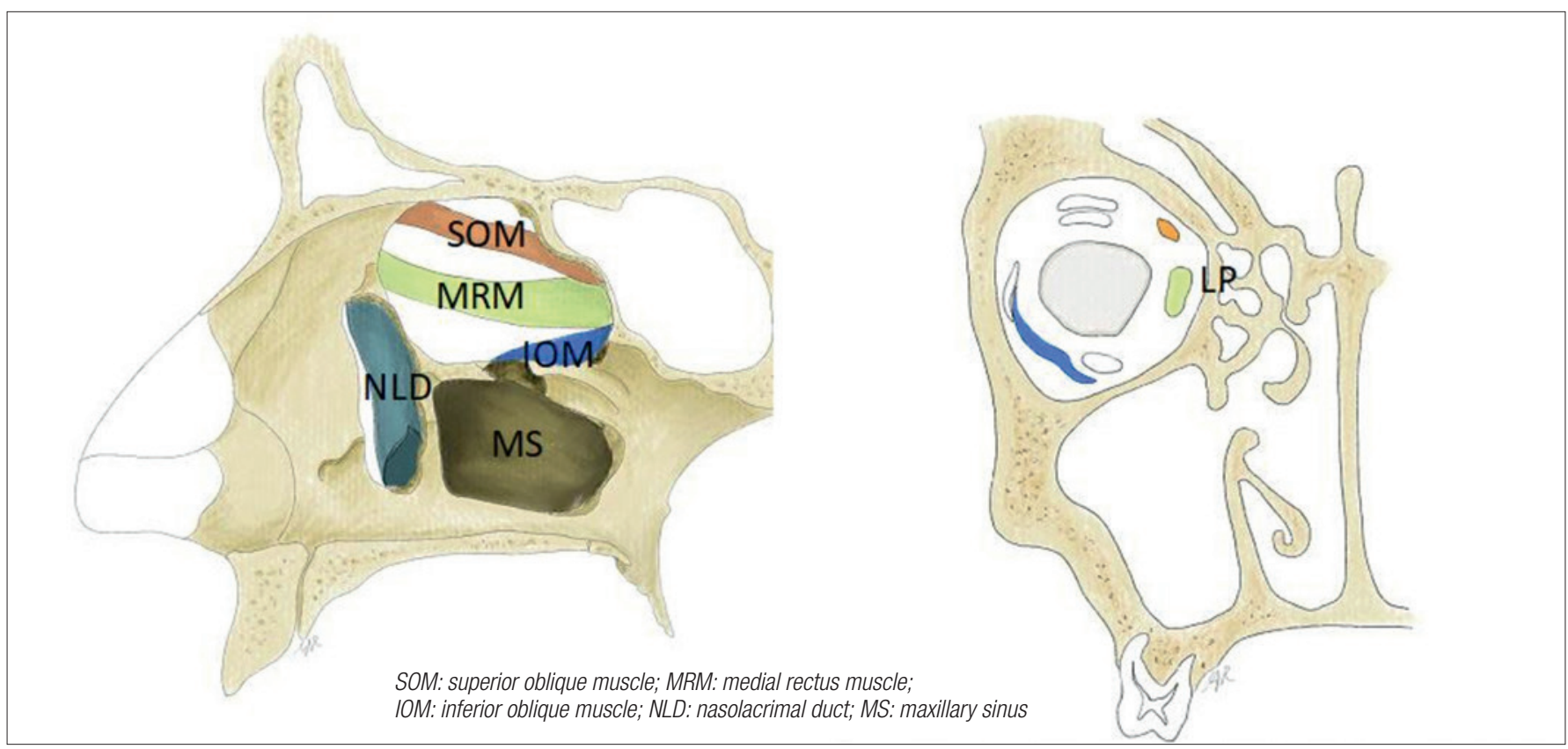

Figure 1. Lamina papyracea (LP) and its relationship with the orbital content (drawing realised by Elisa Aggazzotti Cavazza). 
veins), the extensive venous and lymphatic communication between the sinuses and the surrounding structures enables retrograde thrombophlebitis. This is caused by an increase in pressure, due to the inflammation, that reverts the venous flow, which normally goes towards to the sinus. Although frontal sinusitis alone rarely causes orbital complications, communication from the frontal sinus to the orbit may occur in three sites of dehiscence in the frontal bone: behind the trochlear fossa, behind the supraorbital notch and at the junction of the middle and outer thirds of the sinus floor ${ }^{2,4}$.

Differential diagnosis of orbital involvement includes bacteremia, facial infections, trauma, iatrogenic causes, tumors and dacryocystitis. However, sinusitis is responsible for a least $75 \%$ of cases ${ }^{1}$.

\section{Orbital complications}

Orbital involvement is typically a complication of acute rhinosinusitis (ARS) and is associated, in order of decreasing frequency, with ethmoid, maxillary, frontal and sphenoid sinus infection. Despite oral and intravenous antibiotics have decreased the incidence of this event, orbital infection without appropriate treatment may lead to serious sequelae, including blindness and death. Chandler's classification (Tab. I) distinguishes orbital complications according to the extent of infection into the structures surrounding the orbit and the orbital content itself ${ }^{2,3}$.

Preseptal cellulitis (PC) describes an infection limited to the skin and subcutaneous tissues of the eyelid, anterior to the orbital septum. The orbital septum is a membranous sheet that fuses with the levator palpebrae on the upper eyelid and with the tarsal plate on the inferior eyelid. It is the most common and least severe complication, especially in children, and results from impeded venous and lymphatic drainage from the obstructed sinus.

Orbital (or post-septal) cellulitis (OC) is an infectious process that occurs within the orbit, behind the orbital septum, that occurs when an increase in sinus venous pressure is transmitted to the orbital vasculature, resulting in transudation and leakage through the vessel walls. The orbital content shows diffuse edema, without abscess formation. Subperiosteal abscess (SPA) most commonly develops in the medial orbit when an ethmoidal sinusitis breaks through the LP or travels through the ethmoidal foramina, and create a collection in the subperiosteal space. A SPA could expand rapidly and may lead to blindness by compromising optic nerve function through several possible mechanisms: direct optic nerve compression, elevation of intraorbital pressure, or proptosis.

Orbital abscesses (OA) may occur inside or outside the muscle cone, when orbital cellulitis coalesces into a collec-
Table I. Chandler's classification.

\begin{tabular}{lc}
\hline I & Preseptal cellulitis \\
III & Orbital cellulitis \\
IV & Subperiosteal abscess \\
V & Orbital abscess \\
\hline
\end{tabular}

tion of pus. This rare condition occurs when OC diagnosis is delayed or in immunocompromised patients.

Cavernous sinus thrombosis (CST) results from the direct retrograde spread of infection from nasal cavities (sphenoid $>$ ethmoid $>$ frontal) through the superior and inferior ophthalmic veins, or also as an OC complication.

In a large review on 465 pediatric patients with orbital complications, nearly $50 \%$ had PC, $35 \%$ had OC, $15 \%$ had SPA and fewer than $1 \%$ had an $\mathrm{OA}^{6}$. This illustrates that in the antibiotic era, $\mathrm{PC}$ is the most common orbital complication of ARS. The most commonly isolated organisms in children are S. pneumoniae, $H$. influenzae, $M$. catarrhalis, and $S$. aureus. The adult population differs in the polymicrobial and anaerobic nature of the pathogens and in the most commonly odontogenic origin of infection.

Mucoceles of the paranasal sinuses represent another possible inflammatory source of orbital complication. Mucoceles are chronic cystic lesions, covered with columnar epithelium, that grow within the cavity of the sinus. They originate as an accumulation of mucoid secretion and desquamated epithelium inside the sinus with distension of its walls. The most frequent cause is the obstruction of the sinus ostium due to inflammatory processes, tumors or surgical interventions. The sinuses most commonly involved are the frontal, the ethmoid, the maxillary and the sphenoid, in decreasing order ${ }^{7,8}$.

\section{Clinical features}

PC usually presents with eyelid swelling and erythema without impaired visual acuity. Diagnosis relies on clinical inspection and CT scans. which are only used when symptoms do not improve by 72 hours of antibiotic, since it is unusual for untreated PC to progress to OC.

Clinical presentation of OC may include orbital pain, proptosis and ocular motility impairment, without visual acuity symptoms. In PC the local examination, which may evoke pain and be difficult due to swollen eyelids, does not show globe displacement, as opposed to OC and SPA.

SPA is suspected when a patient with OC develops worsening proptosis and gaze restriction. The ability to distinguish colors may be used as a guide of disease progression because increasing intraorbital pressure causes loss of red/ green perception before deterioration of visual acuity. In children up to 9 years, SPA is likely to respond to antibi- 
otic therapy, since it is usually due to a single aerobic pathogen. Also medial abscesses are highly amenable to antibiotic treatment, whereas more superiorly located abscesses (which tend to occur in older children) carry a greater risk of associated intracranial spread. Considering the lack of frontal sinus aeration in younger patients, especially patients with frontal sinusitis are more prone to intracranial extension through the diploic veins, which run across the orbit to the dural compartment.

OA may be clinically indistinguishable from OC. It may present with more severe proptosis, globe displacement, and ophthalmoplegia related to inflammation of the oculomotor muscles, and patients are more likely to appear toxic. Infection may extend to the orbital apex, causing decreased visual acuity, or intracranially.

CST is a potentially life-threatening complication; although in proximity to the orbit, it is de facto considered an intracranial complication. Even with rapid recognition and treatment, this condition may rapidly progress to loss of vision, meningitis, and death. Intracranial involvement may present with oculomotor nerve palsies, mental status changes, contralateral cranial nerve palsy, or bilateral orbital cellulitis. Headache is the most common symptom and generally precedes fever and periorbital signs.

It is of paramount importance that facial pain is interpreted considering the main sinonasal inflammatory entities ${ }^{9}$. Careful ophthalmologic and neurologic examination with attention to the cranial nerves should be performed, as the oculomotors nerves and the internal carotid artery could be involved. Around $60-70 \%$ of patients with CST will have an abnormal fundoscopic exam with papilledema or dilated retinal veins noted ${ }^{10}$. Extension of phlebitis into the cavernous sinus results in a progression of the process to the opposite eye, a distinguishing feature of CST.

Mucoceles may have variable presentation: a sphenoidal mucocele commonly presents with headache and visual loss, while in fronto-ethmoidal mucoceles, ophtalmic symptoms are frequent (proptosis, diplopia, reduced ocular motility and epiphora). Maxillary mucoceles may present with enophtalmos and globe proptosis $7,8,10,11$.

\section{Radiologic assessment}

CT scan and MRI represent the two complementary imaging modalities for the assessment of the orbital cavity. Radiological appearance according to Chandler's classification is depicted in Table II.

It is possible to encounter clinical conditions whose radiological expressions overlap, especially when paranasal cavities do not seem involved. Differential radiological diagnosis includes the whole spectrum of infiltrative inflammatory pathologies, such as pseudotumor and sarcoidosis, especially as regards PC and OC. Not to forget is the metastatic infiltration of the retrobulbar adipose tissue, such as in breast cancer, which clinically expresses itself with enophthalmos instead of exophthalmos. When the cavernous sinus is involved, Toulouse-Hunt syndrome must be considered. Conversely, there are inflammatory diseases, such as fungal infections or mucoceles, whose radiological expression can be expansive rather than infiltrative, thus simulating the presence of a neoplasm. In post-traumatic infectious processes, orbital hematomas could simulate a mycetoma or abscess (both subperiostal and intra-orbital), especially in the subacute phase.

Another inflammatory lesion with radiological behaviour similar to expansive lesions is the mucocele. This pathology has the characteristics of a chronic process; therefore, local invasiveness predominates over diffusion in the perilesional soft tissues. Its content consists of proteinaceous mucous secretions, thus the cavity is completely obliterated, airless and expanded, with remodelling of the bone based on demineralization rather than erosion. CT scan is the method of choice; in MRI the T1 and T2 signal varies considerably, increasing the $\mathrm{T} 1$ hyperintensity and the $\mathrm{T} 2$ hypointensity in relation to the density of the secretions. In post-contrast images, the mucosal wall has a slight enhancement, which often becomes irregular if superinfection is present. Being a chronic process, the main radiological differential diagnoses are indolent lesions such as inclusion cysts (dermoid/epidermoid) or chronic post-traumatic hematomas (Figs. 2, 3).

Table II. Radiological features of the main orbital complications from sinonasal inflammatory disorders.

\begin{tabular}{|c|c|}
\hline Chandler scale & Radiologic characteristics \\
\hline Pre-septal cellulitis & Periorbital tissues swelling with paranasal sinuses involvement on CT. No contrast needed \\
\hline Orbital cellulitis & $\begin{array}{l}\text { "Stranding" of the intraorbital adipose tissue both at CT and MRI; contrast needed to differentiate } \\
\text { edema from cellulitis and abscess }\end{array}$ \\
\hline Subperiosteal abscess & $\begin{array}{c}\text { DWI restriction of extraconal collections on MRI. Possible association with retrobulbar cellulitis or } \\
\text { involvement of extrinsic muscles or optic nerve. Contrast needed }\end{array}$ \\
\hline Orbital abscess & Same MRI features as SPA, but with intraconal location \\
\hline Cavernous sinus thrombosis & Bulging of the cavernous sinus with reduced contrast enhancement on both CT and MRI \\
\hline
\end{tabular}




\section{Management}

In the treatment of orbital complications, a crucial point is whether to choose a conservative or non-conservative protocol. When planning the treatment, clear communication between the otorhinolaryngologist, neuroradiologist, ophtalmologist, neurosurgeon and maxillo-facial surgeon is critical and timesensitive. Despite difficult in ill children with periorbital oedema, baseline eye examinations is critical: serial eye examinations should be completed by an experienced team member, preferably the same individual, since the treatment choices heavily relies on the validity of this examination.

According to a systematic review focusing on orbital complications, consensus has been found in the PC management: the large majority of cases resolve after broad-spectrum antibiotic therapy. Also OC has been found responsive to pharmacological approach in $77-100 \%$ of the pediatric population ${ }^{10}$. The management of the SPA is more controversial. In the pediatric population, some authors stated that surgery is not always the first choice. Garcia and Harris defined the criteria for management of patients with SPA. They found a $93 \%$ response rate in medically managed selected patients $(<9$ years of age, with a medial, small SPA of nondental origin, and without optic nerve impairment, gas in abscess space, frontal sinusitis or chronic sinusitis) ${ }^{12}$. Other authors have sought to use medical therapy in all SPA patients without preselecting surgical cases, demonstrating that only $26 \%$ could be managed without surgical intervention ${ }^{13}$.

Clearly, there are patients in whom immediate surgery is indicated, such as child with large SPA or OA, marked proptosis, multiple fields of restricted gaze, reduced visual acuity, afferent papillary defect or immunocompromised status. At the present state, however, there is no consensus on what ocular criteria predict the success of medical management ${ }^{13}$.

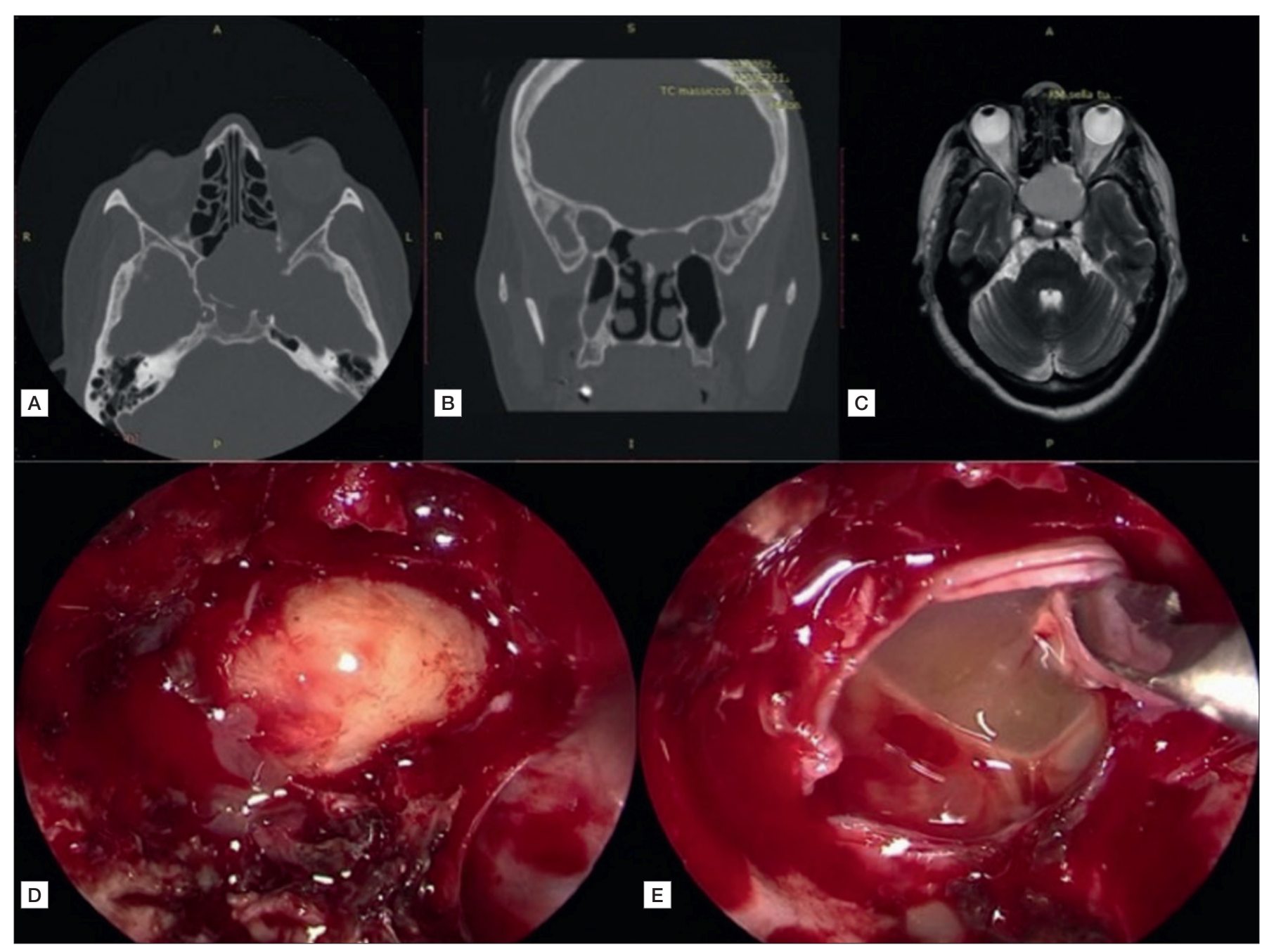

Figure 2. CT scan (A and $\mathbf{B}$ ) and MRI (C) of a sphenoidal mucopyocele with bone erosion of optic foramen, lamina papyracea, orbital apex, carotid canal and sella turcica. Intraoperative view of the mucopyocele sac before (D) and after (E) its endoscopic drainage. 

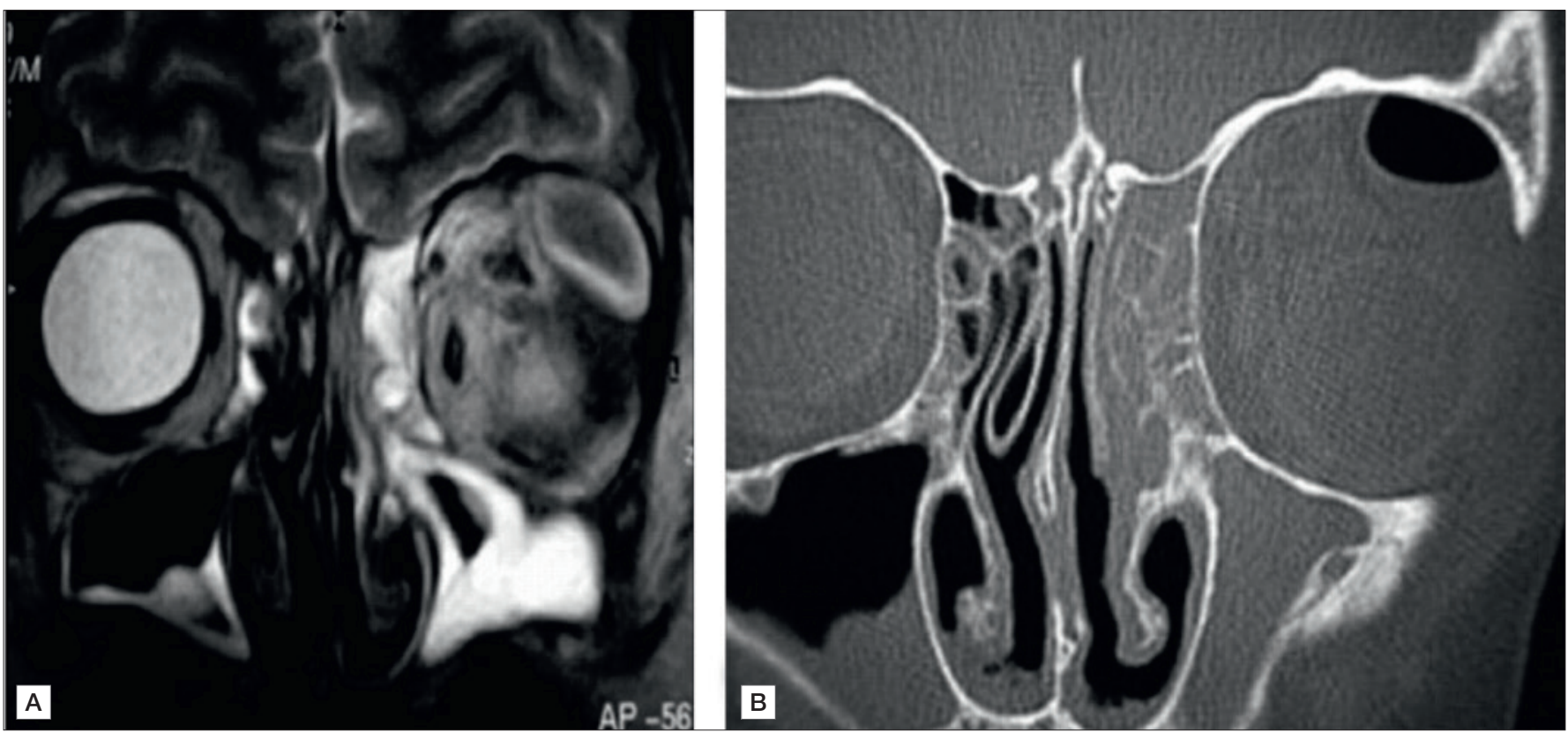

Figure 3. MRI (A) and CT scan (B) of left pansinusitis with orbital abscess.

Few studies in literature address management of OA, due to its rarity nowadays. In general, prompt antibiotic therapy in association with surgical drainage is mandatory. An aggressive surgical approach is always recommended also in case of CST, since neurological and vascular complications can be lethal, while the role of anticoagulants and steroids remains controversial. A proposal for a management algorithm for pediatric patients with SPA or OA is presented in Figure $4{ }^{14}$.

\section{Surgical techniques}

The aims of surgical management of orbital complications include:

- draining the purulent collection;

- addressing the offending sinuses, enlarging their natural ostia;

- obtaining intraoperative cultures.

Decompression of one or more orbital walls may be necessary if orbital pressure remains elevated despite drainage procedure. Both endoscopic or external approaches may be performed, with the surgeon weighing the advantages and disadvantages of each approach. The surgeon should always be prepared to convert an endoscopic approach to an external one if needed and this eventuality should be included in the informed consent. In particular, external approaches could benefit from a multidisciplinary team, consisting of otorhinolaryngologist, ophthalmologist, maxillofacial surgeon, and neurosurgeon.

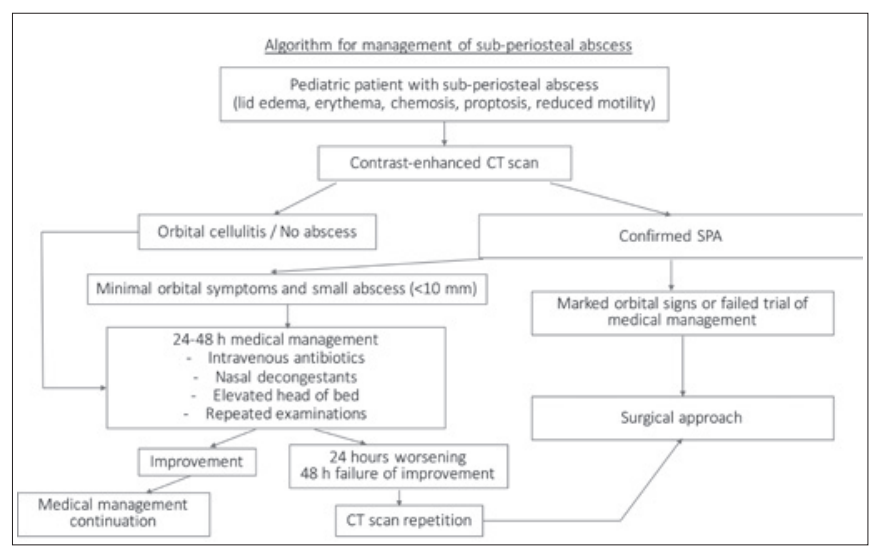

Figure 4. Management algorithm for pediatric patients with suspected subperiosteal or orbital abscess. CT, computed tomography; SPA, subperiosteal abscess (from Bedwell, Bauman, $2011^{14}$, mod.).

Historically, open drainage via Lynch incision, combined with external ethmoidectomy, was the preferred way for draining SPA and OA.

In 1993, Manning reported a successful endoscopic approach, consisting of ethmoidectomy, maxillary antrostomy and limited opening of the LP ${ }^{15}$.

Since then, numerous studies have confirmed the endoscopic approach as a well-tolerated and effective method for management of medial SPA. The main limitation is related to the bleeding potential of the inflamed mucosa, which may seriously compromise visualization, especially 
in pediatric nose and even for experienced endoscopists. Meticulous dissection and identification of landmarks, possibly with the support of image navigation systems, should be employed to prevent injury to noble structures.

The endoscopic procedure for SPA involves anterior and posterior ethmoidectomy associated with frontal sinusotomy and maxillary antrostomy, with the aim of exposing the LP.

After the uncinated process is removed and the ethmoidal bulla is opened, the LP should be visualized and carefully skeletonized with through-cutting instruments in preparation for the abscess drainage. Sometimes pus can be seen streaming from the orbit during ethmoidectomy, through a natural dehiscence or a crack in the LP, especially when orbital pressure is elevated. Drainage of the pus may be initiated by cracking the LP with a Cottle or freer elevator.

Access through the orbital medial wall may be allowed also by a diamond cutter, to reduce its thickness and facilitate removal, reducing the risk of periorbita damage.

It is advisable to preserve a few millimeters of LP anteriorly (just posterior to the bony canal of the nasolacrimal duct) to avoid injuring the trochlea of the trochlear muscle, while posteriorly the dissection should reach an imaginary line that corresponds to the sphenoethmoidal recess.

An incision of the periorbita is necessary to drain an OA. This should be done using a sharp sickle knife, with the tip of the knife remaining superficial; a horizontal incision is made from posterior to anterior, following a line between the lower third and the middle third of the periorbita, to preserve the medial rectus muscle. The intraconal adipose tissue is spread apart to ensure maximum drainage of the abscess collection with immediate decrease in intraorbital pressure. In both operations, there is no need to reconstruct the orbital wall since it is soon replaced by a thick scar tissue. In a patient with high intraorbital pressure the surgeon should be prepared to perform a wide orbital decompression in addition to the endoscopic drainage.

Despite the widespread adoption of endoscopic techniques, a role for open drainage remains. Occasionally, restrictive anatomy combined with florid inflammation may make endoscopic manipulation impossible. Tanna et al. in 2008 reported that $29 \%$ of patients who required SPA surgical drainage underwent a combined open/endoscopic approach, and a further $38 \%$ underwent open drainage only ${ }^{16}$. Those who underwent an open approach were more likely to have superolateral abscess, and demonstrated more extensive muscle involvement than the endoscopic group. Also Migirov et al. examined 22 children with medial SPA subjected to endoscopic versus open approach. The endoscopic group had no postoperative sequelae, whereas the external group experienced facial scarring, delayed healing, stitch abscess, unresolved diplopia, or recurrent cellulitis. The authors recommended exclusive use of endoscopic drainage for medial SPA with an external approach reserved for drainage of superior $\mathrm{OA}{ }^{17}$. Another study by Yang and coworkers confirmed that in cases of laterally seated SPA or when OC is associated with ophthalmoplegia or visual loss, decompression and drainage of the orbit should be performed with no delay through an external approach ${ }^{19}$. Gavriel et al. found that location of abscess dictates the surgical approach: for more anterolateral collections, a combined approach is indicated, while for posterior localization an endonasal approach is more suitable ${ }^{19}$.

Many approaches are indicated to perform external ethmoidectomy and/or anterior orbitotomy, although the most common remains the Lynch incision. A $2.5-3 \mathrm{~cm}$ curvilinear incision is made midway between the medial canthus and nasion, under the eyebrow and anterior to the lacrimal sac, taking care not to transect the supratrochlear and supraorbital nerves. A Z-plasty can be done to reduce scar retraction. The angular artery is encountered deep in the incision and it is ligated. The orbit is lateralized, taking care not to injure the periorbita, exposing the periosteum of the medial orbital wall. This is elevated and separated from the LP. It is important to identify the fronto-ethmoidal suture line, which works as a landmark corresponding to the level of the cribriform plate and the anterior and posterior ethmoidal foramina. Once the vessels are ligated, ethmoidectomy is obtained by perforating the LP immediately behind the posterior lacrimal crest, keeping below the frontoethmoidal suture; this ethmoidotomy provides direct access to the anterior ethmoid. Then ethmoidectomy is completed by opening the floor of the ethmoid bulla directing posteriorly ${ }^{21}$. In alternative, transconjunctival and transcaruncolar approaches have been described with excellent cosmetic outcomes, compared to the Lynch incision.

\section{Conclusions}

Although severe clinical evolutions are far less common in the post-antibiotic era, a worsening in the ophthalmological function must be carefully considered as a landmark in candidacy to surgical drainage. Orbital complications of sinonasal inflammatory disorders need a multidisciplinary counselling involving ophtalmologists, maxillo-facial surgeons and neuroradiologists (Tab. III).

Imaging and interpretation by a dedicated neuroradiologist is advisable for a correct diagnostic work-up and appropriate surgical approach. When considering endoscopic versus external approaches, the intraoperative availability 
Table III. Final recommendations.

\begin{tabular}{|c|c|}
\hline \multicolumn{2}{|r|}{ Multidisciplinary approach } \\
\hline Pre-septal cellulitis & Optional \\
\hline Orbital cellulitis & $\begin{array}{l}\text { Recommended (ophtalmologist, maxillofacial, infectious disease specialist and neuroradiologist involved for differential } \\
\text { diagnosis and appropriate medical therapy) }\end{array}$ \\
\hline Subperiosteal abscess & $\begin{array}{l}\text { Optional, depending on the location (mandatory maxillofacial and/or ophtalmologist cooperation for superior and lateral } \\
\text { location) }\end{array}$ \\
\hline Orbital abscess & $\begin{array}{l}\text { Optional, depending on the location (mandatory maxillofacial and/or ophtalmologist cooperation for superior and lateral } \\
\text { location, or for intraconal lesions) }\end{array}$ \\
\hline Cavernous sinus thrombosis & Recommended \\
\hline Maxillary mucocele & Optional \\
\hline Sphenoidal mucocele & Optional \\
\hline Frontal mucocele & $\begin{array}{l}\text { Optional, depending on the location (recommended maxillofacial and/or neurosurgical cooperation for lesion extending to } \\
\text { the anterior cranial fossa) }\end{array}$ \\
\hline
\end{tabular}

of ophthalmologist, maxillofacial surgeon or neurosurgeon is extremely helpful and encouraged, since the surgeon should always be prepared to convert to an external approach if needed.

\section{References}

1 Aygun N, Zinreich SJ. Radiology of the nasal cavity and paranasal sinuses. In: Flint PW, Haughey BH, Lund VJ, et al., editors. Cummings Otolaryngology. Head and Neck Surgery. Sixth edition. Philadelphia: Saunders; 2015. pp. 662-681.

2 Chandler J, Langenbrunner D, Stevens E. The pathogenesis of orbital complications in acute sinusitis. Laryngoscope 1970;80:1414-1428. https://doi.org/10.1288/00005537-197009000-00007

3 Marchioni D, Alicandri Ciufelli M, Trani M, et al. Anatomia chirurgica del naso, dei seni paranasali e del basicranio anteriore. In: Presutti L, editor. La chirurgia endoscopica dei seni paranasali e della base cranica. Quaderni Monografici di Aggiornamento AOOI (Associazione Otorinolaringologi Ospedalieri Italiani), Lecce: TorGraf; 2007. pp. 29-73.

4 Brook I. Microbiology and antimicrobial treatment of orbital and intracranial complications of sinusitis in children and their management. Int J Pediatr Otorhinolaryngol 2009;73:1183-1186. https://doi. org/10.1016/j.ijporl.2009.01.020

5 Höck A. Orbital cellulitis. Dtsch Arztebl Int 2020;117:60. https://doi. org/10.3238/arztebl.2020.060b

6 Ryan JT, Preciado DA, Bauman N, et al. Management of pediatric orbital cellulitis in patients with radiographic findings of subperiosteal abscess. Otolaryngol Head Neck Surg 2009;140:907-911. https://doi. org/10.1016/j.otohns.2009.02.014

7 Mohan S. Frontal sinus mucocele with intracranial and intraorbital extension: a case report. J Maxillofac Oral Surg 2012;11:337-339. https://doi.org/10.1007/s12663-010-0163-z

8 Mowatt L, Foster T. Sphenoidal sinus mucocele presenting with acute visual loss in a scuba diver. BMJ Case Rep 2013;2013:bcr2013010309. https://doi.org/10.1136/bcr-2013-010309
9 De Corso E, Kar M, Cantone E, et al. Facial pain: sinus or not? Acta Otorhinolaryngol Ital 2018;38:485-496. https://doi. org/10.14639/0392-100X-1721

10 Wong SJ, Levi J. Management of pediatric orbital cellulitis: a systematic review. Int J Pediatr Otorhinolaryngol 2018;110:123-129. https:// doi.org/10.1016/j.ijporl.2018.05.006

11 Garber P,Abramson A, Stallman P, et al. Globe ptosis secondary to maxillary sinus mucocele. Ophthalmic Plast Reconstr Surg 1995;11:254260. https://doi.org/10.1097/00002341-199512000-00006

12 Garcia GH, Harris GJ. Criteria for nonsurgical management of subperiosteal abscess of the orbit: analysis of outcomes 1988-1998. Ophthalmology 2000;107:1454-1456. https://doi.org/10.1016/ s0161-6420(00)00242-6

13 Rahbar R, Robson C, Petersen R, et al. Management of orbital subperiosteal abscess in children. Arch Otolaryngol Head Neck Surg 2001;127:281-286. https://doi.org/10.1001/archotol.127.3.281

14 Bedwell J, Bauman NM. Management of pediatric orbital cellulitis and abscess. Curr Opin Otolaryngol Head Neck Surg 2011;19:467473. https://doi.org/10.1097/MOO.0b013e32834cd54a

15 Manning SC. Endoscopic management of medial subperiosteal orbital abscess. Arch Otolaryngol Neck Surg 1993;119:789-791. https:// doi.org/10.1001/archotol.1993.01880190085018

16 Tanna N, Preciado DA, Clary MS, et al. Surgical treatment of subperiosteal orbital abscess. Arch Otolaryngol Head Neck Surg 2008;134:764-767. https://doi.org/10.1001/archotol.134.7.764

17 Migirov L, Yakirevitch A, Bedrin L, et al. Endoscopic sinus surgery for medial orbital subperiosteal abscess in children. J Otolaryngol Head Neck Surg 2009;38:504-508. https://doi. org/10.2310/7070.2009.080247

18 Yang M, Quah BL, Seah LL, et al. Orbital cellulitis in children-medical treatment versus surgical management. Orbit 2009;28:124-136. https://doi.org/10.1080/01676830902765891

19 Gavriel H, Jabrin B, Eviatar E. Management of superior subperiosteal orbital abscess. Eur Arch Otorhinolaryngol 2016;273:145-150. https://doi.org/10.1007/s00405-015-3557-1

20 Fagan J, Sutherland N, Halbrook E. External ethnoidectomy and rontal sinusotomy/Trephine. Open Access Atlas of Otolaryngology, Head \& Neck Operative Surgery 2008 (www.entdev.uct.ac.za). 